C. T. De Souza · E. P. Araújo · P. O. Prada •

M. J. A. Saad • A. C. Boschero • L. A. Velloso

\title{
Short-term inhibition of peroxisome proliferator-activated receptor- $Y$ coactivator-1 $\alpha$ expression reverses diet-induced diabetes mellitus and hepatic steatosis in mice
}

Received: 20 September 2004 / Accepted: 18 April 2005 / Published online: 16 July 2005

(C) Springer-Verlag 2005

\begin{abstract}
Aims/hypothesis: The coactivator of nuclear receptors, peroxisome proliferator-activated receptor- $\gamma$ coactivator-1 $\alpha$ (PGC-1 $\alpha)$ has been implicated in a series of events that contribute to the control of glucose metabolism. We have recently reported the use of a PGC- $1 \alpha$ antisense oligonucleotide (PGC-1 $\alpha \mathrm{AS}$ ) that inhibits up to $60 \%$ of PGC- $1 \alpha$ expression in pancreatic islets, leading to increased insulin secretion. This oligonucleotide was used in this study to try to ameliorate diet-induced type 2 diabetes in a genetically predisposed mouse strain (Swiss mice). Materials and methods: Glucose and insulin tolerance tests, euglycaemic-hyperinsulinaemic clamp, immunoprecipitation assays, immunoblotting assays and immunohistochemistry were used in this investigation. Results: Swiss mice became obese and overtly diabetic after 8 weeks of feeding with chow containing $24 \%$ saturated fat. One daily dose $(1.0 \mathrm{nmol})$ of PGC-1 $\alpha$ AS significantly reduced glucose and increased insulin blood levels without affecting food intake and body weight. These effects were accompanied by a reduced area under the glucose curve during an intraperitoneal glucose tolerance test, an increased constant of glucose decay $\left(K_{\text {itt }}\right)$ during an insulin tolerance test, and an increased glucose consumption rate during a euglycaemic-hyperinsulinaemic clamp. Moreover, mice
\end{abstract}

\author{
C. T. De Souza · E. P. Araújo · P. O. Prada · M. J. A. Saad \\ L. A. Velloso $(\bowtie)$ \\ Department of Internal Medicine, \\ Faculty of Medical Sciences (FCM), \\ State University of Campinas (UNICAMP), \\ Campinas, São Paulo, 13083-970, Brazil \\ e-mail: lavelloso@fcm.unicamp.br \\ Tel.: +55-19-37888022 \\ Fax: $+55-19-37888950$ \\ A. C. Boschero \\ Department of Physiology and Biophysics, \\ State University of Campinas, \\ Campinas, Brazil

\section{A. Velloso} \\ Laboratory of Experimental Gastroenterology-Gastrocentro, \\ State University of Campinas, \\ Campinas, Brazil
}

treated with PGC- $1 \alpha$ AS presented an outstanding reduction of macroscopic and microscopic features of hepatic steatosis. These effects were accompanied by reduced expression or function of a series of proteins involved in lipogenesis. Conclusions/interpretation: PGC- $1 \alpha$ is an attractive target for pharmacological therapeutics in type 2 diabetes mellitus and diet-induced hepatic steatosis.

Keywords Insulin resistance - Obesity - Peroxisome proliferator-activated receptor- $\gamma$ coactivator- $1 \alpha \cdot$ PGC$1 \alpha \cdot$ Steatosis

Abbreviations ACC: acetyl CoA carboxylase - AMPK: AMP-activated kinase $\cdot \mathrm{CBA} / \mathrm{Uni} / \mathrm{C}$ : CBA/Uni mice fed with standard rodent chow $\cdot \mathrm{CBA} / \mathrm{Uni} / \mathrm{F}$ : CBA/Uni mice fed with fat-rich chow - CREB: cyclic AMP response element binding protein $\cdot$ CPT-1: carnitine palmitoyl transferase-1 - FAS: fatty acid synthase $\cdot \mathrm{HNF}-4 \alpha$ : hepatocyte nuclear factor- $4 \alpha$. IR: insulin receptor . ITT: insulin tolerance test - PPAR $\alpha$ : peroxisome proliferator-activated receptor- $\alpha \cdot \operatorname{PPAR} \gamma$ : peroxisome proliferator-activated receptor- $\gamma \cdot \operatorname{PGC}-1 \alpha$ : peroxisome proliferator-activated receptor- $\gamma$ coactivator$1 \alpha \cdot$ PGC- $1 \alpha$ AS: peroxisome proliferator-activated receptor- $\gamma$ coactivator- $1 \alpha$ antisense oligonucleotide . PGC- $1 \alpha$ S: peroxisome proliferator-activated receptor- $\gamma$ coactivator- $1 \alpha$ sense oligonucleotide $\cdot \mathrm{pY}$ : phosphotyrosine $\cdot \mathrm{SW} / \mathrm{Uni} / \mathrm{C}: \mathrm{SW} / \mathrm{Uni}$ mice fed with standard rodent chow $\cdot \mathrm{SW} / \mathrm{Uni} / \mathrm{F}$ : SW/Uni mice fed with fat-rich chow - WAT: white adipose tissue - SRC-1: steroid receptor coactivator-1 - SREBP-1c: sterol-regulatoryelement-binding-protein-1c

\section{Introduction}

Insulin resistance and type 2 diabetes mellitus are the phenotypic results of complex interactions between genetic and environmental predisposing factors $[1,2]$. In recent years, the progressive increase in the prevalence of obesity in populations of several areas of the world has contrib- 
uted enormously to the parallel increase in the prevalence of diabetes mellitus $[2,3]$. Although dietetic and behavioural approaches, associated with the use of currently available drugs, contribute to a certain degree to loss of body weight and improved control of blood glucose levels, the optimal therapeutic approach for diabetes has yet to be developed [4]. In this regard, the search for candidate targets for drug action that may be useful for the control of this metabolic disease is the main focus of much of the current research in this field [4].

Peroxisome proliferator-activated receptor- $\gamma$ coactivator- $1 \alpha(\mathrm{PGC}-1 \alpha)$ is a 795 -amino-acid protein identified in brown adipose tissue and skeletal muscle by a yeast twohybrid system [5]. As a transcriptional coactivator, PGC$1 \alpha$ has several functional domains that participate in protein-protein interaction with PPAR $\gamma$ [5], PPAR $\alpha$ [6], nuclear respiratory factor [7], cyclic AMP response element binding protein (CREB)-binding protein [8], hepatocyte nuclear factor- $4 \alpha$ (HNF-4 $\alpha)$ [9, 10], forkhead transcription factor-1 [11], steroid receptor coactivator-1 [12] and myocyte enhancer factor-2 [13]. Recent studies have implicated PGC- $1 \alpha$ expression in the control of glucose uptake and insulin sensitivity in muscle cells [13] and the liver [6]. Moreover, at least two clinical series have found a correlation between mutations of the Ppargcla (previously known as PGC- $1 \alpha$ gene) and insulin resistance or diabetes $[14,15]$.

In a previous study, we employed an antisense phosphorothioate-modified oligonucleotide to PGC-1 $\alpha$ (PGC$1 \alpha \mathrm{AS})$, which inhibits the expression of this protein by up to $60 \%$ in pancreatic islets and leads to a significant increase in glucose-stimulated insulin secretion [16]. As the development of diabetes in primary insulin-resistant subjects is thought to be a consequence of a failure of the pancreatic beta cell to compensate for the peripheral demand for insulin [17], we used PGC-1 $\alpha \mathrm{AS}$ in an attempt to reverse diet-induced diabetes in a genetically predisposed mouse strain. To our surprise, not only a significant improvement in insulin secretion was achieved, but also increased insulin action in peripheral tissues and an outstanding amelioration of hepatic steatososis.

\section{Materials and methods}

Antibodies, chemicals and buffers

Reagents for SDS-PAGE and immunoblotting were from Bio-Rad (Richmond, CA, USA). HEPES, phenylmethylsulphonyl fluoride, aprotinin, dithiothreitol, Triton X-100, Tween 20, glycerol and bovine serum albumin (fraction V) were from Sigma (St Louis, MO, USA). ${ }^{125}$ I-protein A and nitrocellulose paper (BA85, $0.2 \mu \mathrm{m}$ ) were from Amersham (Aylesbury, UK). Sodium thiopental and human recombinant insulin (Humulin R) were from Lilly (Indianapolis, IN, USA). Anti-insulin receptor (IR) (sc-711, rabbit polyclonal), anti-Akt (sc-1618, goat polyclonal), anti-phosphotyrosine (pY) (sc-508, mouse monoclonal), anti-phospho $\left[\mathrm{Ser}^{473}\right]$ Akt (rabbit polyclonal, sc-7985-R), anti-PGC-1 $\alpha$ (goat polyclonal, sc-5816), anti-fatty acid synthase (FAS) (goat polyclonal, sc-16146), anti-carnitine palmitoyl transferase-1 (CPT-1) (goat polyclonal, sc-20514), anti-HNF-4 $\alpha$ (goat polyclonal, sc-6556) and anti-peroxisome proliferator-activated receptor- $\gamma$ (PPAR $\gamma$ ) (rabbit polyclonal, sc7196) antibodies were from Santa Cruz Biotechnology (Santa Cruz, CA, USA). Anti-phospho [Thr ${ }^{172}$ AMP-activated kinase (AMPK) (rabbit polyclonal, no. 2531S) was from Cell Signaling Technology (Beverly, MA, USA) and anti-phospho $\left[\mathrm{Ser}^{79}\right]$ acetyl CoA carboxylase (ACC) (rabbit polyclonal, no. 07-184) was from Upstate Biotechnology (Charlottesville, VA, USA).

Sense and antisense oligonucleotide treatment protocols

Sense and antisense oligonucleotides (Invitrogen, Carlsbad, CA, USA) were diluted to a final concentration of 5.0 $\mu \mathrm{mol} / 1$ in dilution buffer containing $10 \mathrm{mmol} / 1$ Tris $-\mathrm{HCl}$ and $1.0 \mathrm{mmol} / \mathrm{l}$ EDTA. The mice were injected (i.p.) with one daily dose of $200 \mu \mathrm{l}$ dilution buffer containing, or not, sense (PGC- $1 \alpha / \mathrm{S})$ or antisense (PGC- $1 \alpha / \mathrm{AS})$ oligonucleotides. Phosphorothioate-modified oligonucleotides were designed according to the Mus musculus and Rattus norvegicus Ppargcla sequences deposited at the NIHNCBI (http://www.ncbi.nlm.nih.gov/entrez) under the designations BC 066868 and NM 031347, and were composed of sense (5'- TCA GGA GCT GGA TGG C -3') and antisense (5'- GCC ATC CAG CTC CTG A -3'). These oligonucleotides have been tested previously: PGC- $1 \alpha / \mathrm{AS}$ reduced the expression of PGC- $1 \alpha$ by around $60 \%$ in pancreatic islets [16] and around $70 \%$ in skeletal muscle [18].

\section{Experimental protocols}

Male, 4-week-old Swiss (SW/Uni) and CBA/Uni mice, inbred strains, originally imported from the Jackson Laboratory (Bar Harbor, ME, USA) and currently bred at the State University of Campinas Breeding Center were used in all experiments. The investigation followed the University guidelines for the use of animals in experimental studies and conformed to the Guide for the Care and Use of Laboratory Animals published by the US National Institutes of Health (NIH publication no. 85-23, revised 1996). The animals were maintained on a 12 -h artificial light-dark cycle and housed in individual cages. After the acclimatising period (3 days), the animals were randomly divided into four experimental groups: SW/Uni mice fed with standard rodent chow (SW/Uni/C), SW/Uni mice fed with fat-rich chow (SW/Uni/F; composition, see Table 1), $\mathrm{CBA} / \mathrm{Uni}$ mice fed with standard rodent chow (CBA/ Uni/C), and CBA/Uni mice fed with fat-rich chow (CBA/ Uni/F). In the first part of the study the animals were evaluated every 4 weeks for biochemical and hormonal parameters to assess diet-induced modulation of glucose homeostasis. Blood samples were always collected at 11.00 
Table 1 Macronutrient composition of diets

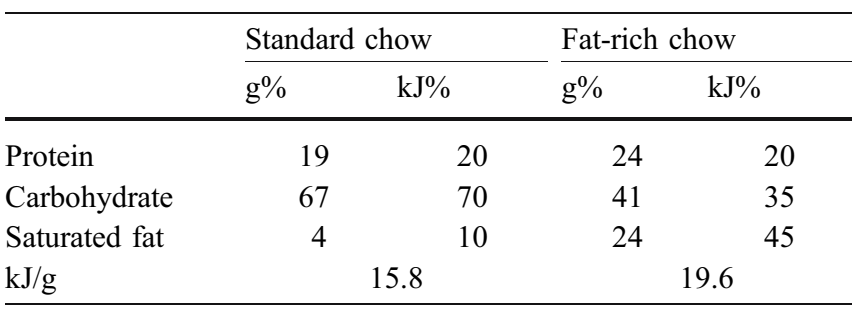

hours, after $4 \mathrm{~h}$ of fasting. Eight weeks of fat-rich diet feeding was set as the time by which all SW/Uni/C mice should have developed diabetes; after this period a second part of the study was started. In this experimental approach, SW/Uni/C and SW/Uni/F were treated either with a daily dose of oligonucleotide dilution vehicle, with PGC- $1 \alpha / \mathrm{S}$ oligonucleotides or with PGC- $1 \alpha / \mathrm{AS}$ oligonucleotides from the 8 th week of the diet onwards. In this part of the study, hormonal and biochemical parameters were evaluated every second day. At day 16 of oligonucleotide treatment, glucose and insulin tolerance tests were performed. Some animals were anaesthetised and tissue was extracted for measurement of PGC- $1 \alpha$ expression, liver histology, triglyceride content, insulin-induced activation of IR and Akt signalling and expression of key proteins of the liver metabolism.

Hormone and biochemical measurements

Plasma insulin was measured by RIA according to a previously described method [19]. Serum glucose was measured by the glucose oxidase method [20]. Serum triglycerides were assessed by colorimetric assays (Wako Chemicals, Neuss, Germany). Liver total lipids were measured by the gravimetric method.

Intraperitoneal glucose tolerance test

After an overnight fast, the mice were anaesthetised, and following the collection of an unchallenged sample (time 0 ), a solution of $25 \%$ glucose ( $11.1 \mathrm{mmol} / \mathrm{kg}$ body weight) was administered into the peritoneal cavity. Blood samples were collected from the tail at 30,60,90 and 120 min for measurement of glucose and insulin concentrations.

Insulin tolerance test

Insulin $(14.5 \mathrm{nmol} / \mathrm{kg})$ was administered by intraperitoneal injection and blood samples were collected at $0,5,10,15$, 20, 25 and $30 \mathrm{~min}$ for measurement of serum glucose. The constant rate for glucose disappearance $\left(K_{\mathrm{itt}}\right)$ was calculated using the formula $0.693 / t_{1 / 2}$. The glucose $t_{1 / 2}$ was calculated from the slope of the least-square analysis of the plasma glucose concentrations during the linear decay phase [21].

\section{Clamp studies}

After a 4-h fast, a 2-h euglycaemic-hyperinsulinaemic clamp study was performed in the lower limb. Under sodium thiopental anaesthesia and aseptic conditions, a mono-occlusive polyethylene catheter was inserted into the femoral artery for infusion of insulin and glucose. A second polyvinyl catheter was inserted into the femoral vein, for blood sampling, and the animal was kept in a heated box $\left(37^{\circ} \mathrm{C}\right)$ throughout the study. During the first phase of the study (30 min), a priming dose of insulin was infused at a rate of $3.6 \mathrm{mU} \mathrm{kg} \mathrm{min}^{-1}$ to achieve steady state concentrations of plasma insulin. After glucose equilibration, insulin infusion was maintained for $2 \mathrm{~h}$ with constant rate, and a variable infusion of glucose ( $5 \%$ solution) was adjusted to maintain the serum glucose concentration at approximately $6.6 \mathrm{mmol} / 1$. Blood samples were collected from the femoral vein every $5 \mathrm{~min}$ for serum glucose measurement and every $30 \mathrm{~min}$ for measurement of plasma insulin. Insulin was measured in duplicate by RIA and oscillated between 0.65 and $15.0 \mathrm{nmol} / \mathrm{l}$ in samples collected from animals of both experimental groups.

\section{Liver histology}

Hydrated, 5.0- $\mu \mathrm{m}$ sections of paraformaldehyde-fixed, paraffin-embedded liver fragments were stained with haematoxylin-eosin, and analysed and photo-documented using an Olympus BX60 microscope.

\section{Immunoprecipitation and immunoblotting}

The abdominal cavities of anaesthetised mice were opened and the animals received an infusion of insulin $(200 \mu \mathrm{l}$, $\left.10^{-6} \mathrm{~mol} / \mathrm{l}\right)$ or saline $(200 \mu \mathrm{l})$ through the cava vein. After different intervals (see Results), fragments $(3.0 \times 3.0 \times$ $3.0 \mathrm{~mm}$ ) of white adipose tissue (WAT) and liver were excised and immediately homogenised in solubilisation buffer at $4^{\circ} \mathrm{C}(1 \%$ Triton X-100, $100 \mathrm{mmol} / 1$ Tris- $\mathrm{HCl}$ [pH 7.4], $100 \mathrm{mmol} / \mathrm{l}$ sodium pyrophosphate, $100 \mathrm{mmol} / \mathrm{l}$ sodium fluoride, $10 \mathrm{mmol} / 1$ EDTA, $10 \mathrm{mmol} / 1$ sodium orthovanadate, $2.0 \mathrm{mmol} / 1$ phenylmethylsulphonylfluoride and $0.1 \mathrm{mg}$ aprotinin/ml) using a Polytron PTA 20S generator (model PT 10/35; Brinkmann Instruments, Westbury, NY, USA). Insoluble material was removed by centrifugation for $20 \mathrm{~min}$ at $9,000 \mathrm{~g}$ in a 70.Ti rotor (Beckman, Fullerton, CA, USA) at $4^{\circ} \mathrm{C}$. The protein concentration of the supernatants was measured by the Bradford dyebinding method. Aliquots of the resulting supernatants containing $5.0 \mathrm{mg}$ of total protein were used for immunoprecipitation overnight with antibodies against IR at $4^{\circ} \mathrm{C}$, followed by SDS-PAGE, transfer to nitrocellulose membranes and blotting with anti-pY antibodies. In direct immunoblot experiments, $0.2 \mathrm{mg}$ of protein extracts obtained from each tissue were separated by SDS-PAGE, transferred to nitrocellulose membranes and blotted with 
anti-IR, anti-Akt, anti-phospho $\left[\mathrm{Ser}^{473}\right] \mathrm{Akt}$, anti-PGC-1 $\alpha$, anti-HNF-4 $\alpha$, anti-phospho [ $\mathrm{Thr}^{172}$ ]AMPK, anti-phospho $\left[\mathrm{Ser}^{79}\right]$ ACC, anti-CPT-1, anti-FAS and anti-PPAR $\gamma$ antibodies. Specific bands were labelled with ${ }^{125}$ I-protein A, as previously described [22]. Visualisation of protein bands was performed by exposure of membranes to RX-films.

\section{Statistical analysis}

Specific protein bands present in the blots were quantified by digital densitometry (ScionCorp, Frederick, MD, USA). Mean values \pm SEM obtained from densitometric scans, and values for insulin, glucose, triglycerides, body weight, glucose consumption rates and food intake were compared using the Tukey-Kramer test (ANOVA). A $p$ value of less than 0.05 was accepted as statistically significant.

\section{Results}

Metabolic characterisation of the animal model

Swiss/SW and CBA are mice strains genetically related to the obesity- and diabetes-prone AKR strain [23]. To evaluate the metabolic consequences of long-term exposure to a fat-rich diet, Swiss (SW/Uni) and CBA (CBA/Uni) mice were fed exclusively with a fat-rich diet (Table 1) from the fourth week of age and compared, every fourth week, with respective controls (fed regular rodent chow), for body weight variation, mean daily food ingestion, serum glucose and plasma insulin. As shown in Fig. 1, SW/Uni fed a fatrich $\operatorname{diet}(\mathrm{SW} / \mathrm{Uni} / \mathrm{F})$ became obese, hyperinsulinaemic and hyperglycaemic after 8 weeks of fat-rich feeding. CBA/Uni fed a fat-rich diet (CBA/Uni/F) also became obese (more than $30 \%$ body weight increase as compared with respective controls, $p<0.05$ ) and hyperinsulinaemic, but did not develop diabetes. Fat-rich feeding did not promote significant changes in mean daily food intake in any of the strains (data not shown).

Ageing and fat-rich diet feeding increased the expression of PGC- $1 \alpha$ in the liver and adipose tissue

To evaluate the effect of fat-rich feeding on the expression of PGC- $1 \alpha, \mathrm{SW} / \mathrm{Uni}$ and CBA/Uni mice fed regular chow or a fat-rich diet were maintained on respective diets for $0,8,12$ or 16 weeks. At the end of predetermined experimental periods, fragments of liver and adipose tissue were obtained for protein extraction and immunoblotting experiments. As shown in Fig. 2, the protein levels of PGC- $1 \alpha$ were very low in both tissues, in SW/Uni and $\mathrm{CBA} /$ Uni mice, before introduction of the experimental diet (at the fourth week of age). Both ageing and a fatrich diet promoted significant increases in PGC- $1 \alpha$ expression in the liver and adipose tissue in the two strains evaluated.
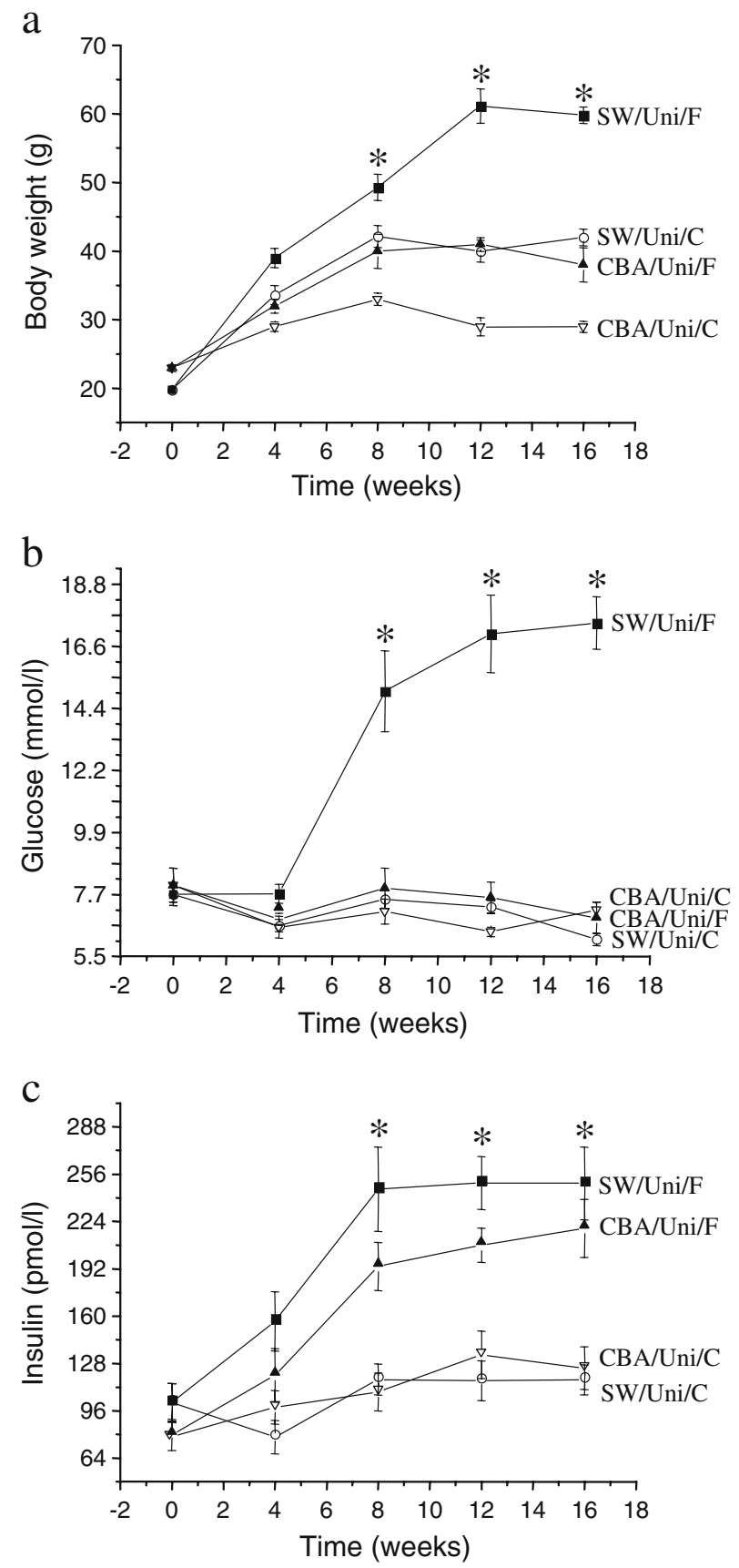

Fig. 1 Body mass (a), serum glucose (b) and plasma insulin (c) levels in SW/Uni and CBA/Uni mice fed a regular (C) or fat-rich (F) diet. Respective diets were introduced at 4 weeks of age and parameters were evaluated every 4 weeks. For all experiments the results are presented as means $\pm \mathrm{SEM}$ of $n=6 ;{ }^{*} p<0.05$ vs. SW/Uni/C mice

Inhibition of PGC- $1 \alpha$ expression reversed diet-induced diabetes

To evaluate the effect of the inhibition of PGC- $1 \alpha$ expression on the glucose homeostasis of SW/Uni mice, a phosphorothioate-modified antisense oligonucleotide to PGC- $1 \alpha$ (PGC- $1 \alpha / \mathrm{AS})$ was used. Given that glucose and insulin levels became significantly higher from 8 weeks 
Fig. 2 Immunoblot evaluation of PGC- $1 \alpha$ expression in the liver and WAT of SW/Uni and CBA/Uni mice fed a regular (control) or fat-rich diet. Mice were introduced to the respective diets at 4 weeks of age (time 0 ). Groups of four mice were randomly selected every 4 weeks (up to 16 weeks) for extraction of liver and WAT protein. Samples containing 0.2 $\mathrm{mg}$ total protein were resolved by SDS-PAGE, transferred to nitrocellulose membranes and blotted with anti-PGC- $1 \alpha$ antibodies. Specific bands were quantified by digital scanning densitometry. For all experiments, $n=4$ and results are presented as mean fold increase in band digital density
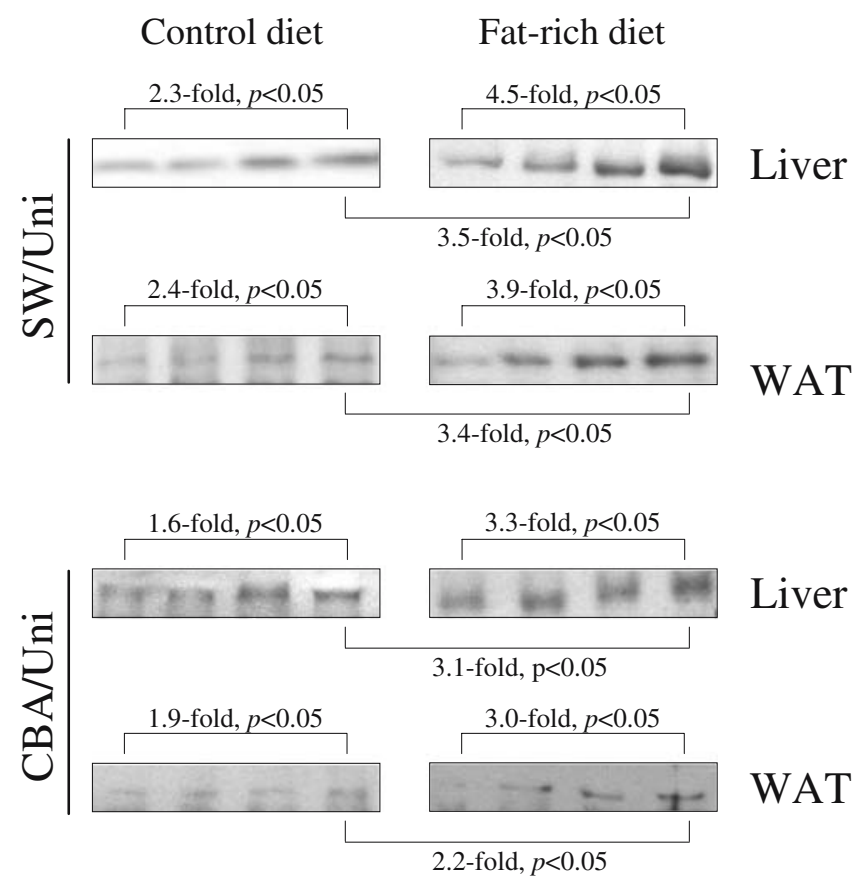

$\begin{array}{lllllllll}\text { Time (weeks) } & 0 & 8 & 12 & 16 & 0 & 8 & 12 & 16\end{array}$ after the introduction of the fat-rich diet in SW/Uni mice, we decided to begin PGC- $1 \alpha / \mathrm{AS}$ treatment from the eighth experimental week onwards. The potency of PGC- $1 \alpha / \mathrm{AS}$ was tested in a dose-response experiment. As shown in Fig. $3 \mathrm{a}$, a daily dose of $0.5 \mathrm{nmol}$ PGC- $1 \alpha / \mathrm{AS}$ was sufficient to inhibit PGC $-1 \alpha$ expression by $44 \pm 7 \%$ and $40 \pm 8 \%(n=4$, $p<0.05$ ), while $2.0 \mathrm{nmol} /$ day resulted in $86 \pm 11 \%$ and 75 $\pm 14 \%(n=4, p<0.05)$ inhibition of PGC- $1 \alpha$ expression in the liver and adipose tissue of $\mathrm{SW} / \mathrm{Uni} / \mathrm{F}$ mice, respectively. One daily dose of $1.0 \mathrm{nmol}$ PGC- $1 \alpha / \mathrm{AS}$ was sufficient to inhibit PGC- $1 \alpha$ expression by $84 \pm 12 \%$ and $70 \pm$ $13 \%(n=4, p<0.05)$ in the liver and adipose tissue of SW/ Uni/F mice, respectively (Fig. 3a,b), and was therefore used in the remaining experiments. PGC- $1 \alpha / \mathrm{AS}$ promoted no significant changes in the expression of the structural proteins actin and vimentin in the liver and adipose tissue, respectively (Fig. 3b). From the eighth day of PGC$1 \alpha /$ AS administration, the levels of serum glucose became significantly lower than control levels and presented a continuous drop until reaching the level of $7.2 \mathrm{mmol} / \mathrm{l}$ at the 14th day (Fig. 3c). The levels of plasma insulin increased significantly from the tenth day of PGC- $1 \alpha / \mathrm{AS}$ treatment (Fig. 3d). PGC-1 $\alpha /$ AS caused no significant changes in body mass and food intake (Fig. 3e,f). However, during an intraperitoneal glucose tolerance test, mice treated with PGC- $1 \alpha / \mathrm{AS}$ presented a reduced area under the glucose curve and an increased area under the insulin curve (Fig. 4a,b), and during an ITT, a higher constant of glucose decay $\left(K_{\text {itt }}\right)$ was observed in PGC- $1 \alpha / \mathrm{AS}$ mice (Fig. 4c). Finally, during a euglycaemic-hyperinsulinaemic clamp, an increase in glucose consumption rate (new rate $75 \%$ ) was observed in PGC-1 $\alpha / \mathrm{AS}$ mice (Fig. 4d).
Improved insulin signal transduction in the liver and adipose tissue of PGC- $1 \alpha / \mathrm{AS}$-treated mice

To evaluate the effect of PGC- $1 \alpha / \mathrm{AS}$ on the activity of the insulin signal transduction pathway, we anaesthetised SW/ Uni/F mice, treated or not with PGC- $1 \alpha / \mathrm{AS}$ for 16 days, and injected a single dose of saline $(200 \mu \mathrm{l})$ or insulin $(200$ $\left.\mu \mathrm{l}, 10^{-6} \mathrm{~mol} / \mathrm{l}\right)$ through the cava vein. After 2 or $5 \mathrm{~min}$, fragments of liver and WAT were obtained and used in typical immunoprecipitation and immunoblotting experiments to assess tyrosine phosphorylation of the IR, and $\left[\mathrm{Ser}^{473}\right]$-phosphorylation of Akt. As depicted in Fig. 5, inhibition of PGC- $1 \alpha$ expression was associated with a significant increase in insulin-induced tyrosine phosphorylation of the IR (Fig. 5a,b) and $\left[\mathrm{Ser}^{473}\right]$-phosphorylation of Akt (Fig. 5c,d) in the liver and adipose tissue. These phenomena were accompanied by increased expression of IR in the liver and adipose tissue and increased expression of Akt in adipose tissue but not in the liver (Fig. 5).

Reversal of diet-induced hepatic steatosis by PGC- $1 \alpha / \mathrm{AS}$

During the preceding experiments, we observed outstanding macroscopic modification in the livers of mice fed a fat-rich diet. The livers of SW/Uni/F mice were yellowish in colour and slightly larger in size. After 16 days of PGC- $1 \alpha / \mathrm{AS}$ treatment, the livers of SW/Uni/F mice recovered their reddish colour and normal size. Four SW/ Uni/F mice treated with PGC- $1 \alpha / \mathrm{AS}, \mathrm{PGC}-1 \alpha / \mathrm{S}$ or vehicle for 16 days were randomly selected for histological 
a

\begin{tabular}{|c|c|c|c|c|c|}
\hline 0 & 0.1 & 0.5 & 1.0 & 2.0 & PGC-1 $\alpha /$ AS (nmol/day) \\
\hline$=$ & 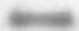 & $=$ & $=0$ &.+ & Liver \\
\hline 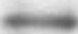 & $\longrightarrow$ & $=$ & $\longrightarrow$ & $2=$ & WAT \\
\hline
\end{tabular}
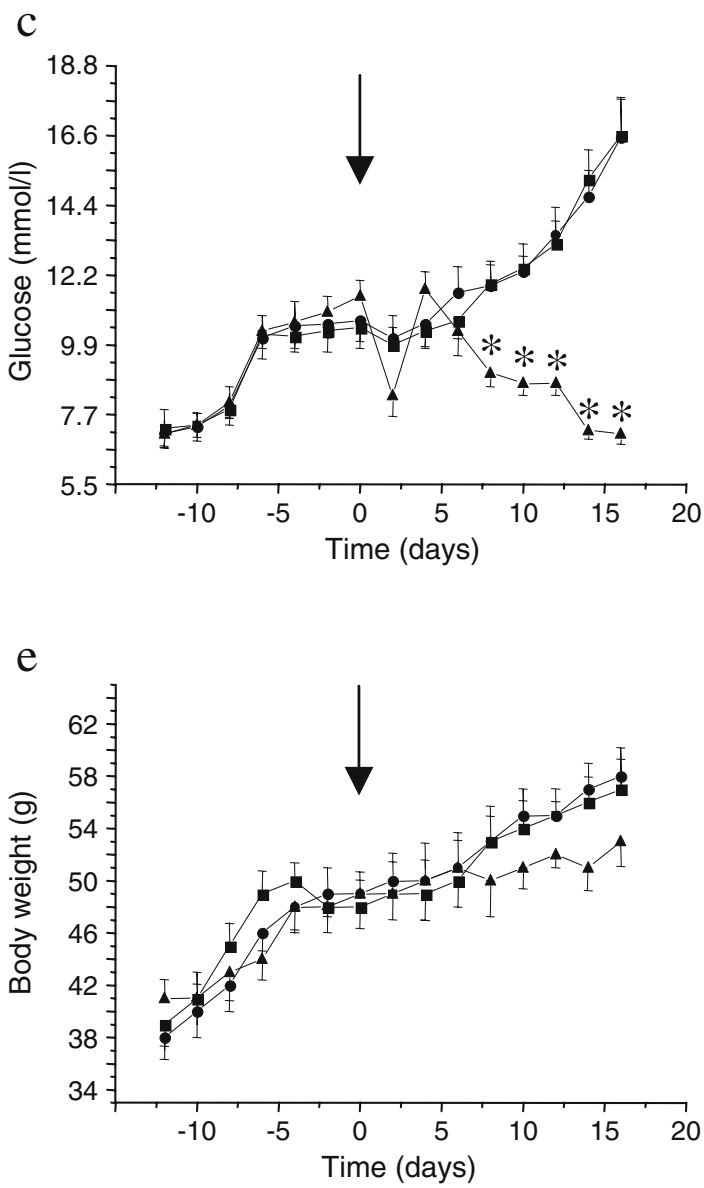

Fig. 3 Clinical and metabolic effects of PGC- $1 \alpha$ expression inhibition. a, b Immunoblot evaluation of PGC- $1 \alpha$ expression in the liver and WAT of SW/Uni mice fed a fat-rich diet and treated with a daily dose of sense (S) or antisense (AS) PGC- $1 \alpha$ oligonucleotide, or vehicle $(\mathrm{C})$. a Dose-response to PGC-1 $\alpha \mathrm{AS}$; doses employed are depicted in the panel. b The dose of PGC- $1 \alpha \mathrm{S}$ and PGC- $1 \alpha \mathrm{AS}$ was $1.0 \mathrm{nmol} /$ day. Liver and WAT protein extracts were obtained after 8 days of treatment and samples containing $0.2 \mathrm{mg}$ protein were resolved by SDS-PAGE, transferred to nitrocellulose membranes and blotted with anti-PGC- $1 \alpha$, anti-actin or anti-vimentin antibodies. $\mathbf{c}-\mathbf{f}$ Evaluation of effects of PGC-1 $\alpha$ expression inhibition

analysis of the liver. As shown in Fig. 6a, SW/Uni/F mice treated with vehicle or PGC- $1 \alpha / \mathrm{S}$ for 16 days presented a steatotic liver, with intra-hepatocyte fat depots predominantly in the perivenular zone with extension to the external areas of the lobule. Treatment with PGC- $1 \alpha / \mathrm{AS}$ b
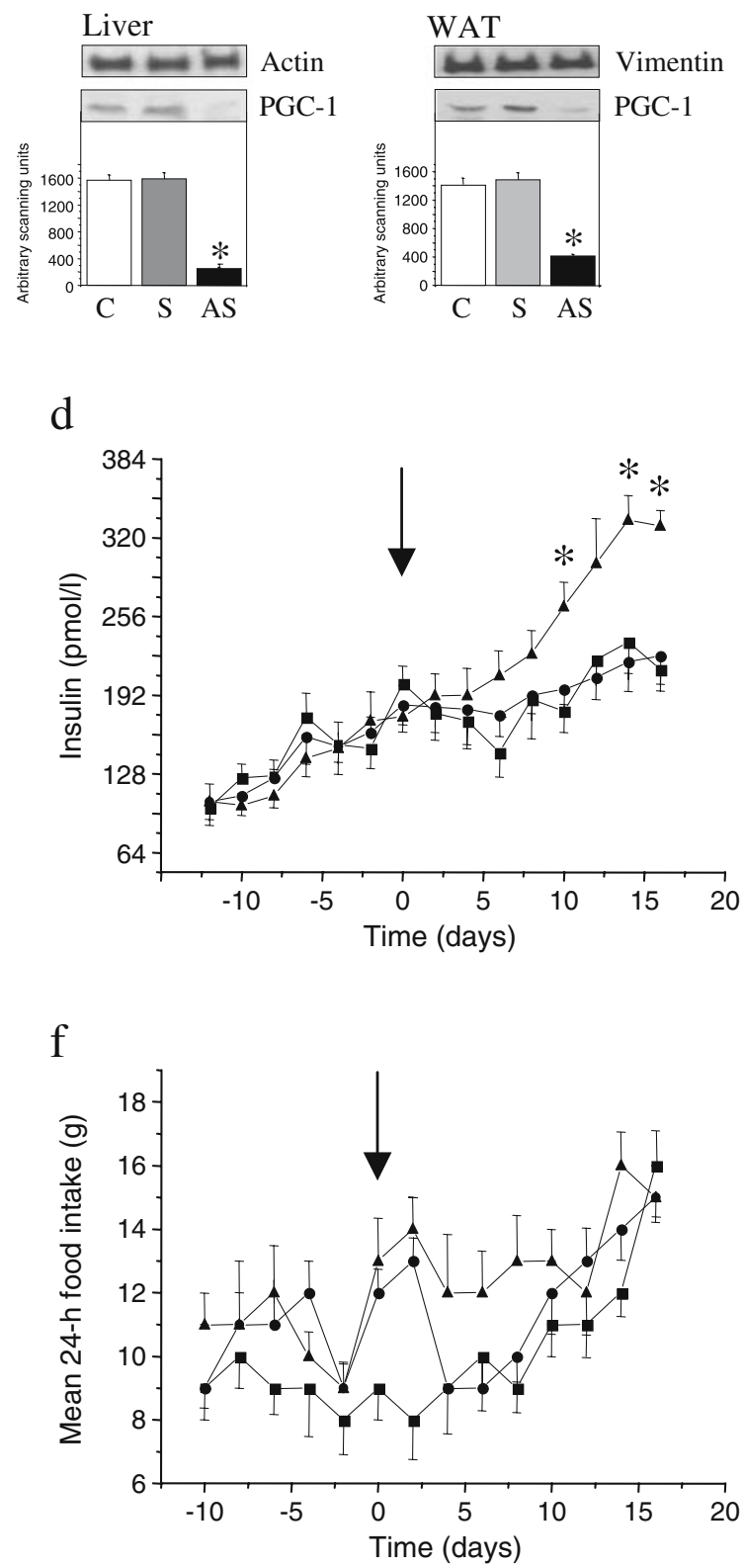

on serum glucose levels (c), plasma insulin levels (d), body mass (e) and mean daily food ingestion (f). In all of these experiments (c-f), groups of six SW/Uni mice fed a fat-rich diet were treated with a single daily dose $(1.0 \mathrm{nmol})$ of PGC- $1 \alpha \mathrm{S}$ (filled circles) or $\mathrm{PGC}-1 \alpha \mathrm{AS}$ (filled triangles) oligonucleotides and compared with controls (filled squares). Measurements (every 4 days) began 12 days before starting treatment with oligonucleotides (first dose of oligonucleotides is marked with the vertical arrow, time 0 ), and continued until the 16th day of oligonucleotide injection. Results are presented as means \pm SEM of $n=4(\mathbf{a}, \mathbf{b})$ or $n=6(\mathbf{c}-\mathbf{f}) ;{ }^{*} p<0.05$ vs. C

almost completely restored the microscopic aspect of the liver (Fig. 6a). In SW/Uni/F mice not treated with PGC$1 \alpha / \mathrm{AS}$, the serum levels of triglycerides were low while the concentration of total lipids in hepatic tissue was high. The treatment with $\mathrm{PGC}-1 \alpha / \mathrm{AS}$ for 16 days promoted 
a
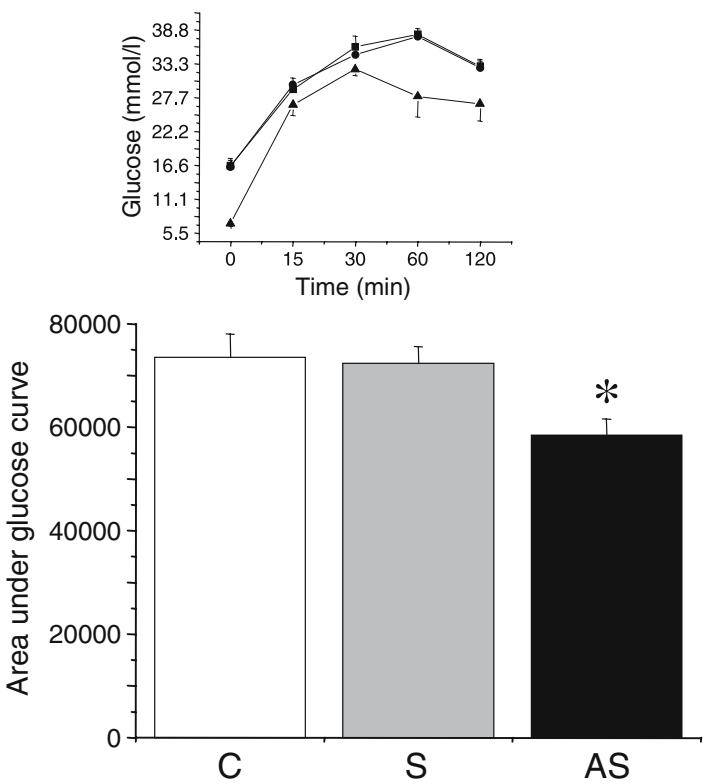

b

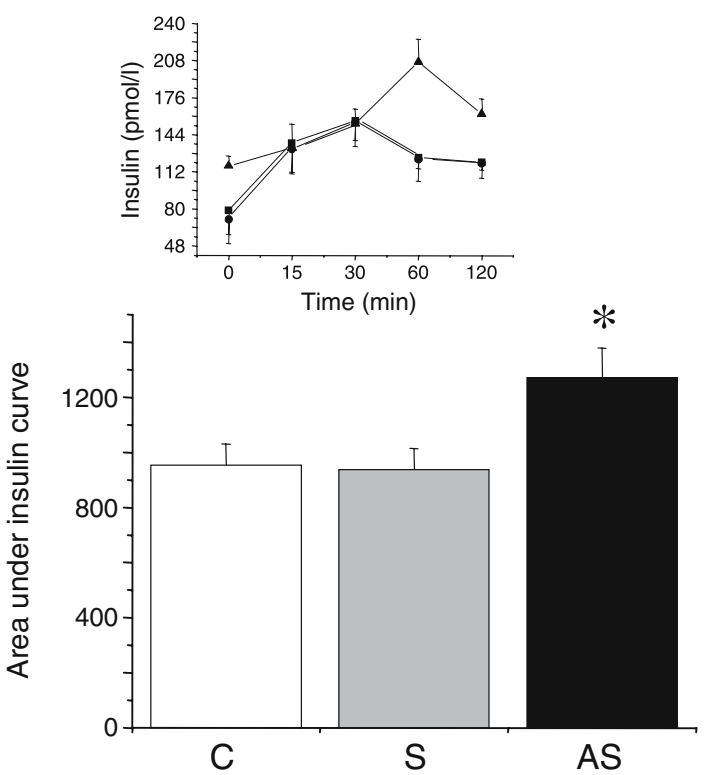

Fig. 4 Clinical and metabolic effects of PGC- $1 \alpha$ expression inhibition. For all experiments, groups of six SW/Uni mice fed a fat-rich diet were treated with a single daily dose $(1.0 \mathrm{nmol})$ of PGC$1 \alpha \mathrm{S}$ (filled circles) or PGC-1 $\alpha \mathrm{AS}$ (filled triangles) oligonucleotides and compared with controls (filled squares). Mice from each group were used for the assessment of the area under the glucose (a) and insulin (b) curves during a glucose tolerance test, or were submitted

significant reduction in liver total fat content but increased the levels of triglycerides in serum (Fig. 6b,c). Finally, the amount of protein (CPT-1, FAS, HNF- $4 \alpha$ and PPPA $\gamma$ ) or the molecular activation status (AMPK and ACC) of proteins involved in key steps of the control of liver lipogenesis and gluconeogenesis were evaluated by typical immunoblot. As expected, fat-rich feeding increased the
$\mathrm{C}$
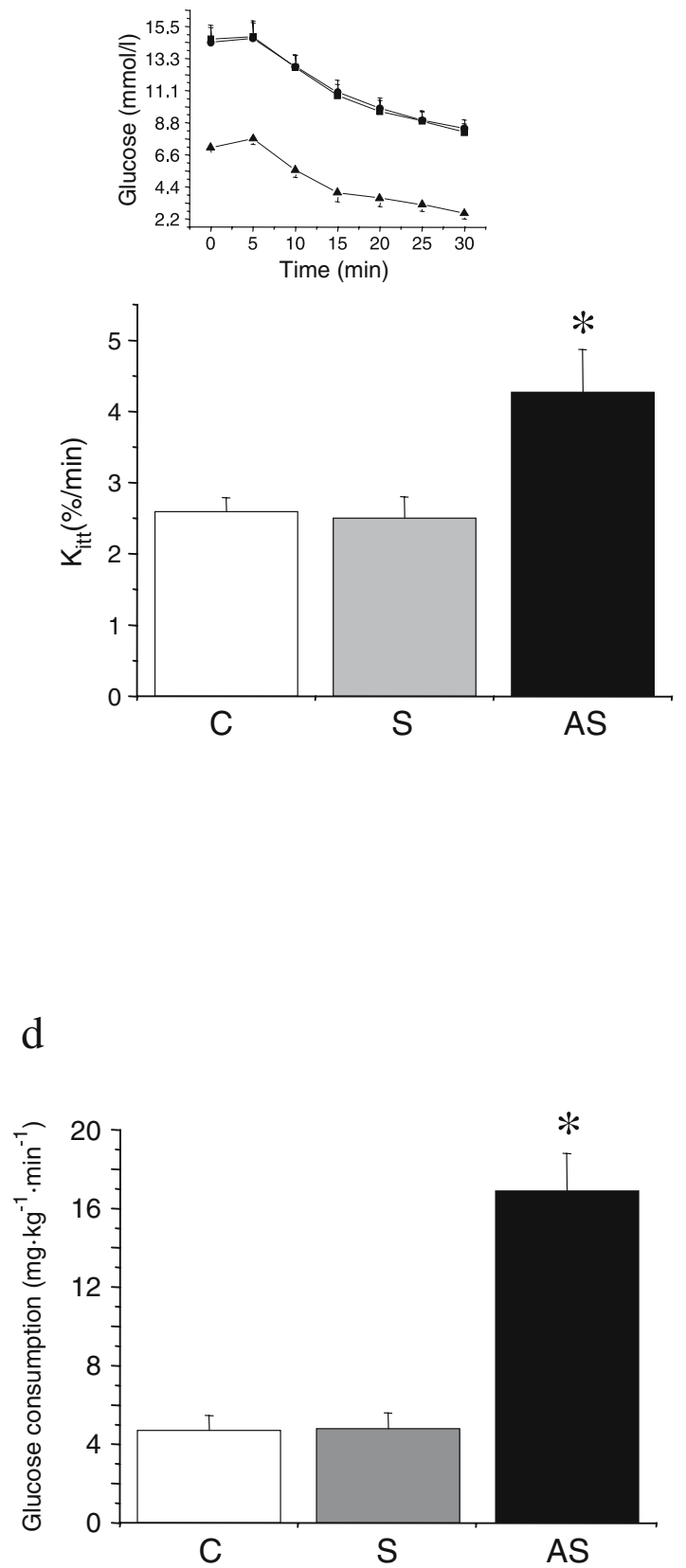

for an ITT and the constant of glucose decay $\left(K_{\text {itt }}\right)$ was calculated (c). The excursion curves for glucose $(\mathbf{a}-\mathbf{c})$ and insulin $(\mathbf{b})$ are depicted as insets. $\mathbf{d}$ The rate of glucose consumption $\left(\mathrm{mg} \mathrm{kg}^{-1} \mathrm{~min}^{-1}\right)$ during a euglycaemic-hyperinsulinaemic clamp is presented. In all experiments the results are presented as means \pm SEM of $n=6 ;{ }^{*} p<$ 0.05 vs. $\mathrm{C}$

molecular activation of AMPK and inhibited the molecular activation of ACC, as measured by [Thr ${ }^{172}$-phosphorylation of the first and $\left[\mathrm{Ser}^{79}\right]$-phosphorylation of the second enzyme (Fig. 6d). Moreover, a fat-rich diet increased the expression of CPT-1, FAS and PPAR $\gamma$, but promoted a significant reduction in HNF- $4 \alpha$ (Fig. 6d). The treatment with PGC- $1 \alpha /$ AS promoted a complete restoration of CPT- 1 and 
a

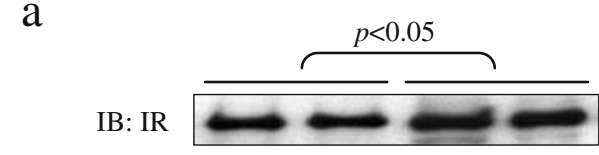

IP: IR; IB: pY

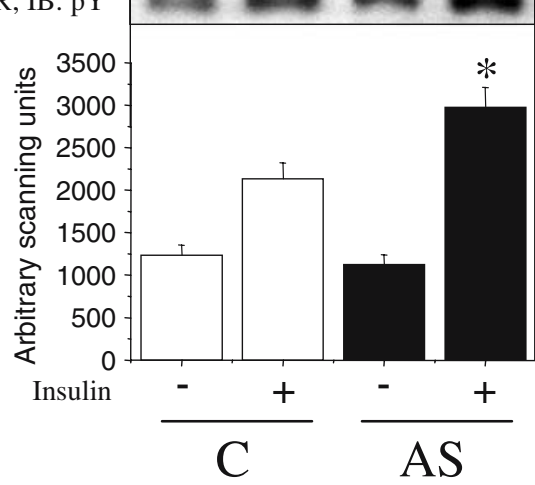

IB: Actin

b

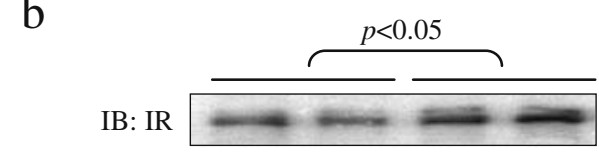

IP: IR; IB: pY

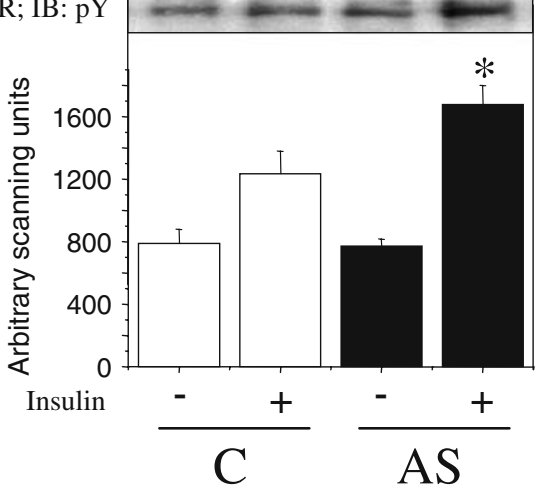

IB: Vimentin

Fig. 5 Analysis of insulin-induced tyrosine phosphorylation of the IR $(\mathbf{a}, \mathbf{b})$ and of insulin-induced $\left[\mathrm{Ser}^{473}\right]$ phosphorylation of Akt $(\mathbf{c}, \mathbf{d})$ in the liver $(\mathbf{a}, \mathbf{c})$ and WAT $(\mathbf{b}, \mathbf{d})$ of SW/Uni mice fed a fat-rich diet and treated (AS) or not (C) with the antisense oligonucleotide to PGC-1 $\alpha$. Mice were treated for 16 days with a single daily dose $(1.0 \mathrm{nmol})$ of oligonucleotide (AS) or vehicle (C). Insulin $(+)\left(200 \mu \mathrm{l}, 10^{-6} \mathrm{~mol} / \mathrm{l}\right)$ or a similar volume of saline $(-)$ was injected through the cava vein, and after $2 \min (\mathbf{a}, \mathbf{b})$ or $5 \min (\mathbf{c}, \mathbf{d})$, fragments of liver and WAT were obtained for protein extraction. a, b Samples containing $5.0 \mathrm{mg}$ were used in immunoprecipitation (IP) experiments with anti-IR antibodies; the immunocomplexes obtained were separated by SDS-PAGE, transferred to nitrocellulose membranes

HNF- $4 \alpha$ levels and restoration of AMPK $\left[\right.$ Thr $\left.^{172}\right]$-phosphorylation and ACC $\left[\mathrm{Ser}^{79}\right]$-phosphorylation to levels similar to those observed in SW/Uni/C mice (Fig. 6d). Finally, in PGC- $1 \alpha /$ AS-treated mice, FAS and PPAR $\gamma$ protein levels dropped to levels below those seen in SW/ Uni/C mice (Fig. 6d).
$\mathrm{C}$
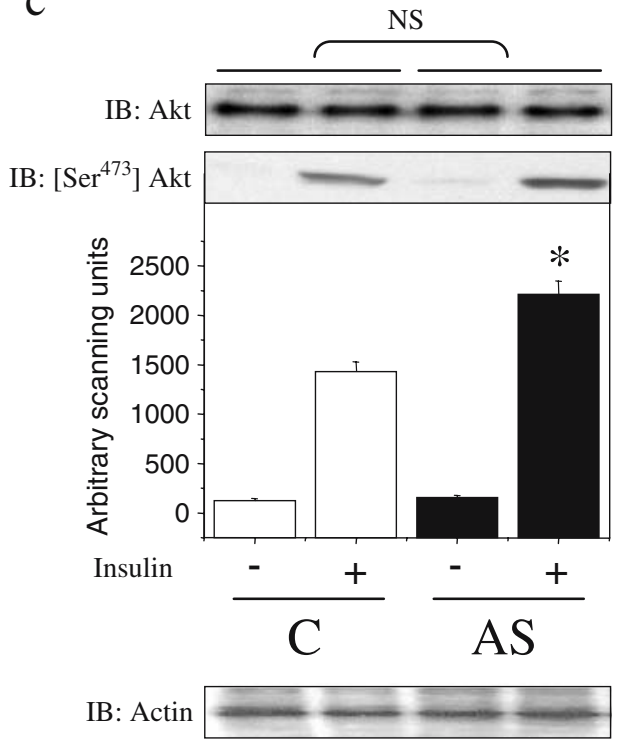

d
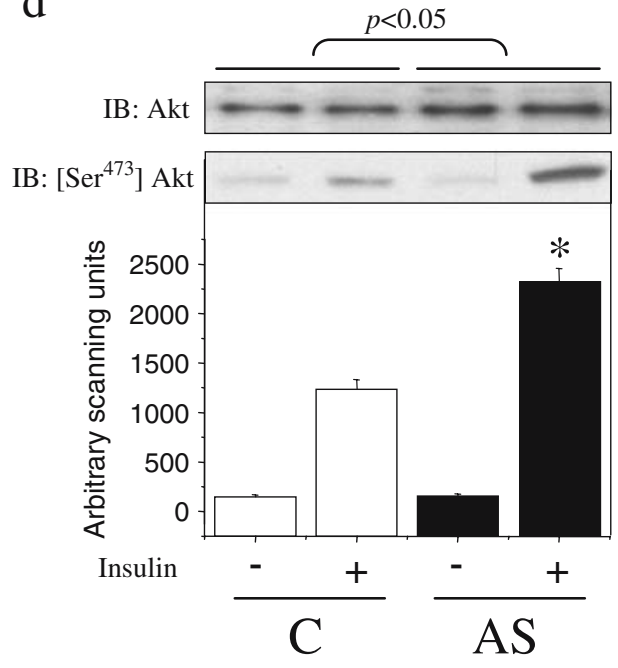

IB: Vimentin

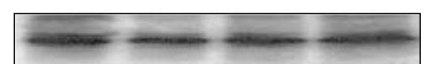

and immunoblotted (IB) with anti-pY antibodies. c, d $0.2 \mathrm{mg}$ protein was resolved by SDS-PAGE, transferred to nitrocellulose membranes and immunoblotted with anti-phospho[Ser $\left.{ }^{473}\right]$ Akt antibody. In all panels, the upper blots were obtained by immunoblotting nitrocellulose transfers of $0.2 \mathrm{mg}$ total protein extracts, separated by SDSPAGE, with anti-insulin receptor $(\mathbf{a}, \mathbf{b})$ or anti-Akt $(\mathbf{c}, \mathbf{d})$ antibodies. In all panels, the lower blots were obtained by reprobing the original nitrocellulose transfers used for IR and Akt assessment (upper blots) with anti-actin (a, c) and anti-vimentin $(\mathbf{b}, \mathbf{d})$ antibodies. Respective bands were quantified by digital densitometry. For all experiments the results are presented as means \pm SEM of $n=4,{ }^{*} p<0.05$ vs. C +

\section{Discussion}

PGC- $1 \alpha$ was first identified as a coactivator of nuclear receptors that participate in the control of thermogenesis, responding directly to environmental thermal oscillations [5]. In recent years, questions have been raised about 
a
Control

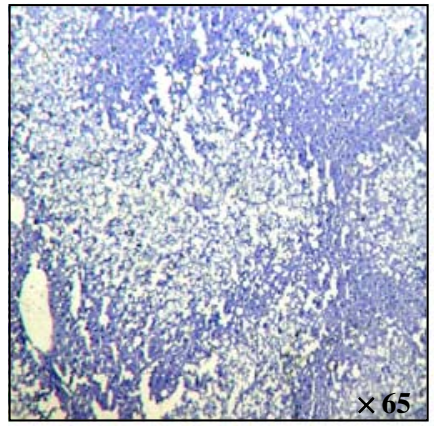

b

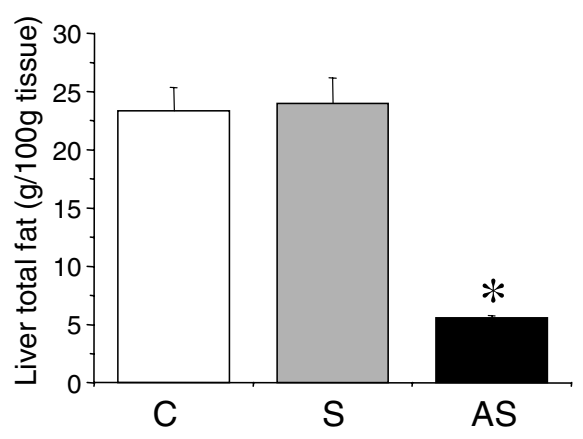

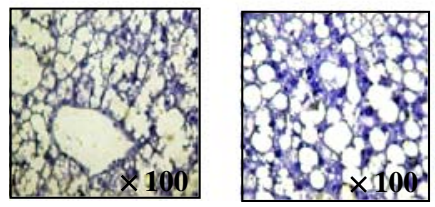

Sense
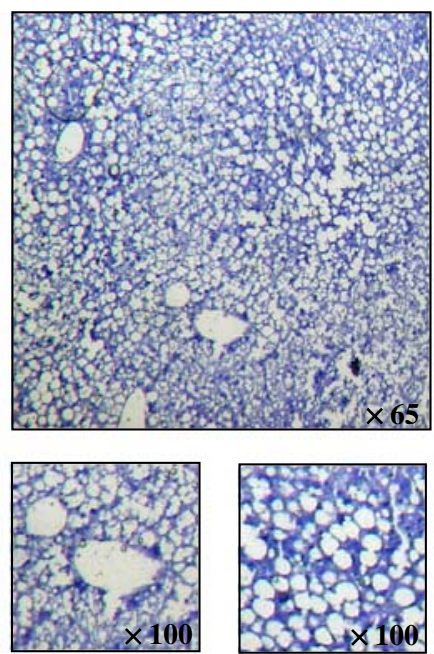

Antisense
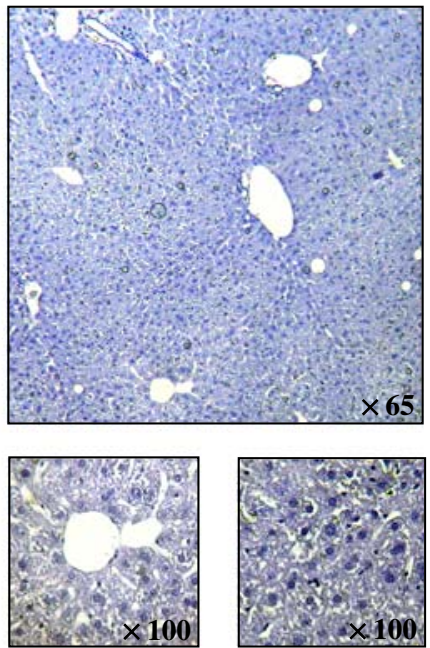

c

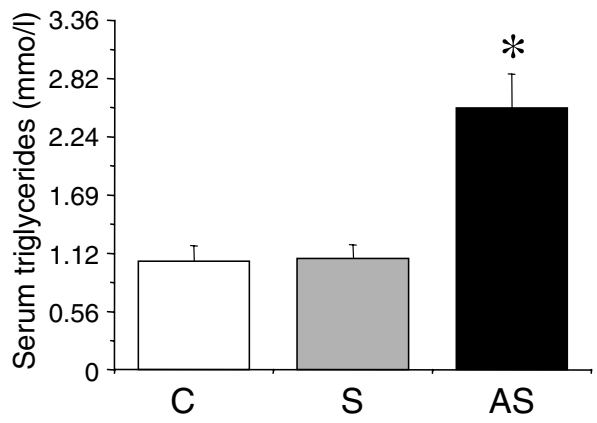

d
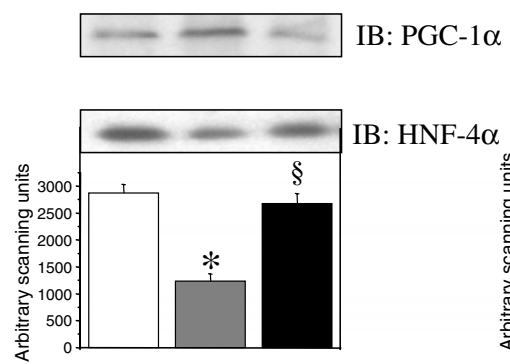

IB: HNF- $4 \alpha$

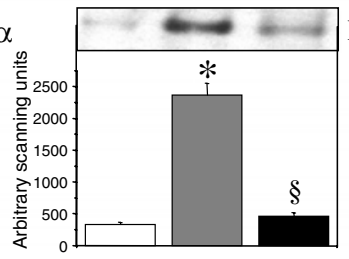

IB: pACC
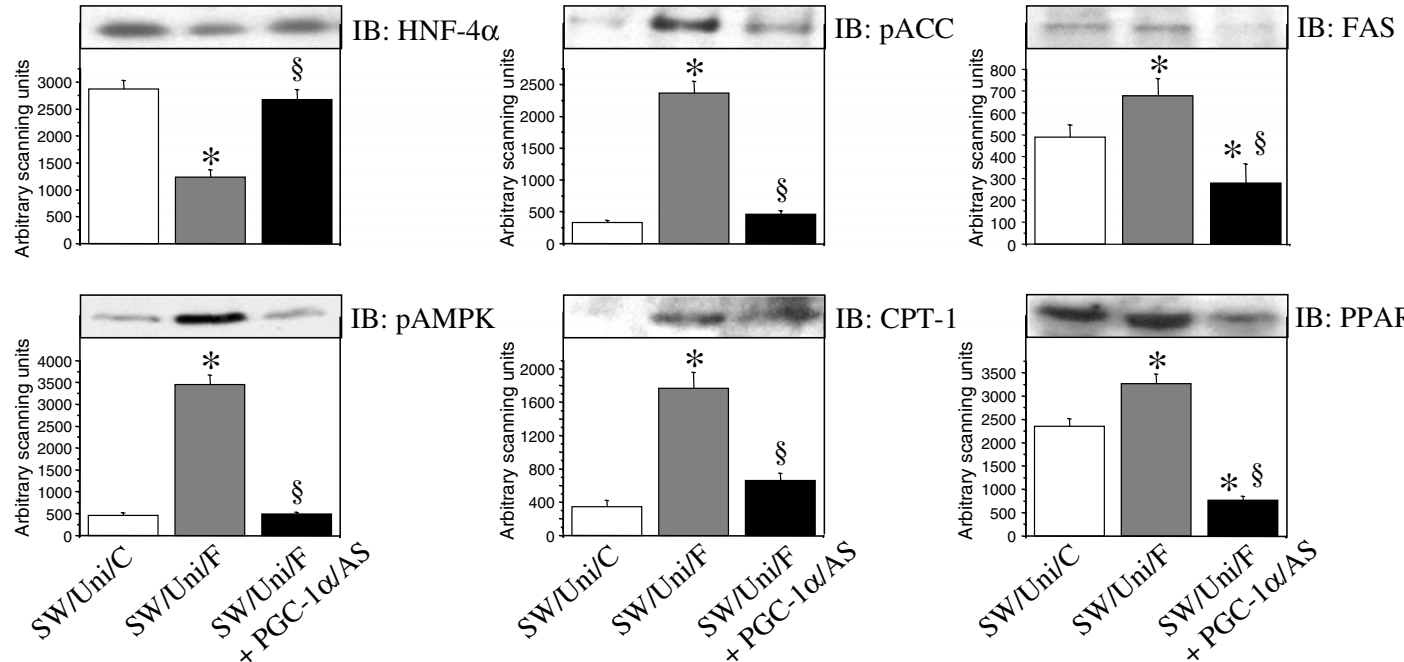

IB: $\mathrm{pAMPK}$
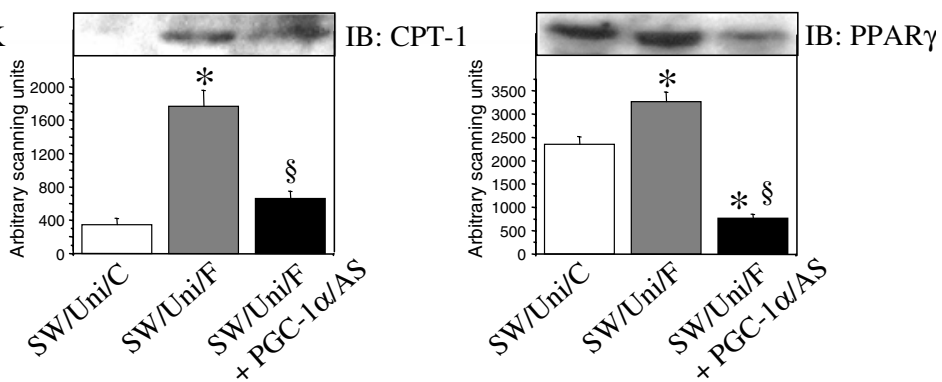

the possible roles played by this protein in tissues not traditionally involved in thermogenesis. Some of these studies have provided important clues regarding a multifaceted and multi-organic role for PGC- $1 \alpha$ in the control of glucose homeostasis [24]. In this context, PGC- $1 \alpha$ was shown to participate in the regulation of hepatic gluconeogenesis [8], in the connection of neural stimuli and beta cell insulin production [16], in the control of muscle glucose 
4Fig. 6 Effects of PGC-1 $\alpha$ expression inhibition on histological and metabolic parameters of the liver. a Haematoxylin staining of 5.0- $\mu \mathrm{m}$ sections of livers obtained from SW/Uni mice fed a fat-rich diet and treated with vehicle (control) or sense or antisense oligonucleotide to PGC- $1 \alpha$ for 16 days. Liver content of total lipids (b) and serum levels of triglycerides (c) were measured in SW/Uni mice fed a fat-rich diet and treated for 16 days with sense (S) or antisense (AS) oligonucleotide to PGC- $1 \alpha$ or with vehicle (C). d The protein amounts of PGC- $1 \alpha$, HNF- $4 \alpha$, CPT-1, FAS and PPAR $\gamma$, the $\left[\mathrm{Thr}^{172}\right]-$ phosphorylation of AMPK, and the [Ser ${ }^{79}$-phosphorylation of ACC were measured in the livers of SW/Uni mice fed a control (SW/Uni/C) or fat-rich diet, and treated (SW/Uni/F+PGC-1 $\alpha / \mathrm{AS})$ or not (SW/Uni/ F) with the PGC-1 $\alpha$ AS oligonucleotide by immunoblot (IB) of nitrocellulose membranes containing the transfers of liver total protein extracts resolved by SDS-PAGE. a The figures are representative of four different experiments. $\mathbf{b}-\mathbf{d}$ Results are presented as means \pm SEM for $n=6(\mathbf{b}, \mathbf{c})$ and $n=4(\mathbf{d}) ;{ }^{*} p<0.05$ vs. C

uptake [18] and in the modulation of adipose tissue insulin signalling [25].

As a participant of the transcriptional control of several programs related to glucose metabolism and energy mobilisation, PGC- $1 \alpha$ has become an interesting potential target for therapeutics in diabetes, obesity and related diseases. Therefore, we decided to employ a PGC- $1 \alpha$ antisense oligonucelotide to study the effects of the inhibition of whole-body PGC- $1 \alpha$ expression on some clinical parameters of diet-induced diabetes. Previous studies have demonstrated that the AKR-related [23] SW/Uni mouse strain develops diabetes, hyperinsulinaemia and obesity when fed a fat-rich diet (M. J. Saad, unpublished data). In the first part of the study, we confirmed the predisposition of SW/Uni mice to diabetes and showed that this is not a common feature of all strains related to AKR mice, since CBA/Uni mice developed obesity and hyperinsulinaemia but not diabetes. It is interesting to note that, like in many humans, the mice strains evaluated here depend on a combination of environmental and genetic factors to present the complete obesity and diabetes phenotype [26]. Thus, they become attractive models to study these complex diseases [27].

We next evaluated the effects of a fat-rich diet on the expression of PGC- $1 \alpha$ in the liver and adipose tissue of the two mice strains. At 4 weeks of age, the levels of PGC- $1 \alpha$ are very low in both tissues of both strains. However, ageing as well as consumption of a fat-rich diet promoted significant increases in PGC- $1 \alpha$ expression in the liver and adipose tissue. Moreover, the magnitude of the increases in PGC- $1 \alpha$ expression owing to ageing and diet seemed to be more pronounced in the SW/Uni mice than in the CBA/Uni strain.

By treating the SW/Uni/F mice with a single daily dose of $1.0 \mathrm{nmol}$ PGC- $1 \alpha / \mathrm{AS}$, we obtained an almost complete inhibition of PGC- $1 \alpha$ expression in the liver and adipose tissue. The effectiveness of this antisense oligonucleotide was surprising, and even a dose as low as $0.5 \mathrm{nmol} /$ day was capable of significantly reducing the expression of the target protein. As a result, we observed a complete remission of hyperglycaemia after 16 days. This effect was a consequence of increased insulin production and improved peripheral insulin action as assessed by functional tests and the evaluation of important steps of the insulin signalling pathway. Interestingly, the inhibition of PGC- $1 \alpha$ expression was accompanied not only by improved signal transduction through IR and Akt, but also by an increased expression of IR and Akt in the liver and of IR in adipose tissue. Thus, the inhibition of PGC- $1 \alpha$ exerts a coordinated effect to amplify insulin signalling, acting simultaneously upon protein expression and functional activation. However, at this time, we cannot be sure whether the effect of PGC- $1 \alpha$ inhibition on IR and Akt expression occurs at transcriptional levels, at translational levels, or perhaps at both levels.

The ability of PGC- $1 \alpha$ to inhibit insulin secretion by pancreatic islets has been previously shown $[16,28]$. Sympathetic tonus generated by the exposure of experimental animals to a cold environment, or a direct stimulus of isolated pancreatic islets with the adrenergic agonist clonidine, increases PGC- $1 \alpha$ expression in islets and reduces glucose-stimulated insulin secretion. Inhibition of PGC- $1 \alpha$ expression partially restores the capacity of beta cells to secrete insulin [16]. Furthermore, adenoviral induction of PGC- $1 \alpha$ in pancreatic islets reduces insulin secretion [28]. Finally, in several animal models of diabetes, the expression of PGC- $1 \alpha$ is increased, coinciding with the suppression of proteins involved in beta cell metabolism and production of ATP $[16,28]$. Therefore, we were not surprised that the inhibition of PGC- $1 \alpha$ in the animal model presented here produced an increase in insulin secretion.

Conversely, the effect of PGC- $1 \alpha$ suppression upon whole-body insulin action was unexpected. Using three distinct methods, ITT, euglycaemic-hyperinsulinaemic clamp and evaluation of insulin-induced molecular activation of IR and Akt in fat and the liver, we observed an improvement in insulin function in SW/Uni/F mice treated with PGC- $1 \alpha /$ AS. Few studies have evaluated the role of PGC- $1 \alpha$ in WAT, and the data available indicate that its expression in this tissue activates a transcriptional program that induces mitochondria biogenesis and promotes a phenotypical and functional shift towards brown adipocyte [29]. Moreover, some studies have suggested a correlation between the level of expression of PGC- $1 \alpha$ in WAT and insulin action $[25,30]$. However, no study has evaluated whether PGC- $1 \alpha$ expression in WAT plays a mechanistic role or is a consequence of insulin resistance. In this context, Coulter and coworkers [31] have shown that the consumption of dietary fat, which leads to insulin resistance, imposes a regulation upon PGC- $1 \alpha$ expression that is different in brown and white adipose tissue.

In contrast to the limited information available regarding the roles for PGC- $1 \alpha$ in WAT, enormous progress in the characterisation of PGC- $1 \alpha$ functions in the liver has occurred in recent years. In this tissue, induction of PGC$1 \alpha$ participates in the late regulation of gluconeogenesis during prolonged fasting $[9,32]$. It does so by acting as a coactivator of transcriptional factors that induce the expression of gluconeogenic proteins such as phosphoenolpyruvate carboxylase and G6Pase $[8,9]$. To exert this function, PGC- $1 \alpha$ depends on the expression of HNF- $4 \alpha$ [9]; in the absence of HNF- $4 \alpha$ PGC- $1 \alpha$ may participate in the control of the expression of other genes, but not of 
gluconeogenic genes $[9,32]$. In parallel to its involvement in gluconeogenic pathways, PGC- $1 \alpha$ also plays an important role in the complex mechanisms that coordinate lipid storage and oxidation in the liver [33]. During fasting, in parallel to the increased expression of PGC- $1 \alpha$ the transcription factor CREB is induced in response to cortisol and glucagon [33]. The induction of CREB imposes a negative regulation upon the expression of PPAR $\gamma$ which results in increased lipid oxidation and reduced lipogenesis [33]. In the present study, we demonstrate that with a fatrich diet, the hepatic expression of lipogenic genes is significantly increased while the expression of HNF- $4 \alpha$ is inhibited. When PGC- $1 \alpha$ expression is blunted, a rapid reversal of the macroscopic and microscopic features of steatosis is achieved and this is accompanied by a reduction in the expression of genes involved in lipogenesis. In contrast, the expression of HNF- $4 \alpha$ is restored. Of particular interest is the finding that inhibition of PGC- $1 \alpha$ leads to a remarkable reduction of FAS expression. In this context, in a recent study, Oberkofler and colleagues showed that PGC- $1 \alpha$ induces the expression of the sterol-regulatory-element binding protein- $1 \mathrm{c}$ and, through this mechanism, regulates the expression of FAS and ACC [34].

Although we did not measure the hepatic production of glucose, we show that the molecular activation of Akt is reduced, and several studies have demonstrated the association of steatosis and hepatic insulin resistance [35, 36]. In a recent study, PGC- $1 \alpha$ was shown to induce hepatic insulin resistance through $\operatorname{PPAR} \alpha$, a protein known to be hyperexpressed in diet-induced steatotic livers [6, 37]. Therefore, the consumption of a high-fat diet stimulates liver lipogenesis and induces insulin resistance in association with increased PGC- $1 \alpha$ expression. Inhibition of PGC- $1 \alpha$ expression reduces lipogenesis while ameliorating molecular parameters of insulin action. The net result is the reversal of diet-induced diabetes and improvement of histological steatosis, but with increased levels of blood triglycerides.

In conclusion, the present study demonstrates that in contrast to previous ideas, not only hepatic, but, at least in certain clinical conditions, whole-body PGC- $1 \alpha$ may be an attractive target for therapeutics in diabetes and related diseases.

Acknowledgements These studies were supported by grants from The State of São Paulo Research Foundation (FAPESP) and the national research commission Conselho Nacional de Pesquisa (CNPq). We are indebted to Dr N. Conran for English grammar editing.

\section{References}

1. Goldstein BJ (2003) Insulin resistance: from benign to type 2 diabetes mellitus. Rev Cardiovasc Med 4(Suppl 6):S3-S10

2. Zimmet P, Alberti KG, Shaw J (2001) Global and societal implications of the diabetes epidemic. Nature 414:782-787

3. Flier JS (2004) Obesity wars: molecular progress confronts an expanding epidemic. Cell 116:337-350

4. Moller DE (2001) New drug targets for type 2 diabetes and the metabolic syndrome. Nature 414:821-827
5. Puigserver $\mathrm{P}, \mathrm{Wu} \mathrm{Z}$, Park $\mathrm{CW}$, Graves R, Wright $\mathrm{M}$, Spiegelman BM (1998) A cold-inducible coactivator of nuclear receptors linked to adaptive thermogenesis. Cell 92:829-839

6. Koo SH, Satoh H, Herzig S et al (2004) PGC-1 promotes insulin resistance in liver through PPAR-alpha-dependent induction of TRB-3. Nat Med 10:530-534

7. Wu Z, Puigserver P, Andersson U et al (1999) Mechanisms controlling mitochondrial biogenesis and respiration through the thermogenic coactivator PGC-1. Cell 98:115-124

8. Herzig S, Long F, Jhala US et al (2001) CREB regulates hepatic gluconeogenesis through the coactivator PGC-1. Nature 413: $179-183$

9. Yoon JC, Puigserver P, Chen G et al (2001) Control of hepatic gluconeogenesis through the transcriptional coactivator PGC-1. Nature 413:131-138

10. Yamamoto T, Shimano H, Nakagawa Y et al (2004) SREBP-1 interacts with hepatocyte nuclear factor-4 alpha and interferes with PGC-1 recruitment to suppress hepatic gluconeogenic genes. J Biol Chem 279:12027-12035

11. Puigserver P, Rhee J, Donovan J et al (2003) Insulin-regulated hepatic gluconeogenesis through FOXO1-PGC-1alpha interaction. Nature 423:550-555

12. Chang E, Bartholomeusz G, Pimental R et al (1999) Direct binding and in vivo regulation of the fission yeast $\mathrm{p} 21$-activated kinase shk1 by the SH3 domain protein scd2. Mol Cell Biol 19:8066-8074

13. Michael LF, Wu Z, Cheatham RB et al (2001) Restoration of insulin-sensitive glucose transporter (GLUT4) gene expression in muscle cells by the transcriptional coactivator PGC-1. Proc Natl Acad Sci U S A 98:3820-3825

14. Ek J, Andersen G, Urhammer SA et al (2001) Mutation analysis of peroxisome proliferator-activated receptor-gamma coactivator-1 (PGC-1) and relationships of identified amino acid polymorphisms to Type II diabetes mellitus. Diabetologia 44: $2220-2226$

15. Hara K, Tobe K, Okada T et al (2002) A genetic variation in the $P G C-1$ gene could confer insulin resistance and susceptibility to Type II diabetes. Diabetologia 45:740-743

16. De Souza CT, Gasparetti AL, Pereira-da-Silva M et al (2003) Peroxisome proliferator-activated receptor gamma coactivator1-dependent uncoupling protein-2 expression in pancreatic islets of rats: a novel pathway for neural control of insulin secretion. Diabetologia 46:1522-1531

17. Porte D Jr, Kahn SE (2001) beta-cell dysfunction and failure in type 2 diabetes: potential mechanisms. Diabetes 50(Suppl 1): S160-S163

18. Oliveira RL, Ueno M, de Souza CT et al (2004) Cold-induced PGC-1alpha expression modulates muscle glucose uptake through an insulin receptor/Akt-independent, AMPK-dependent pathway. Am J Physiol Endocrinol Metabol 287:E686E695

19. Scott AM, Atwater I, Rojas E (1981) A method for the simultaneous measurement of insulin release and B cell membrane potential in single mouse islets of Langerhans. Diabetologia 21:470-475

20. Trinder P (1969) Determination of blood glucose using an oxidase-peroxidase system with a non-carcinogenic chromogen. J Clin Pathol 22:158-161

21. Bonora E, Manicardi V, Zavaroni I, Coscelli C, Butturini U (1987) Relationships between insulin secretion, insulin metabolism and insulin resistance in mild glucose intolerance. Diabetes Metab 13:116-121

22. Gasparetti AL, de Souza CT, Pereira-da-Silva M et al (2003) Cold exposure induces tissue-specific modulation of the insulinsignalling pathway in Rattus norvegicus. J Physiol 552:149-162

23. Rossmeisl M, Rim JS, Koza RA, Kozak LP (2003) Variation in type 2 diabetes-related traits in mouse strains susceptible to diet-induced obesity. Diabetes 52:1958-1966

24. Puigserver P, Spiegelman BM (2003) Peroxisome proliferatoractivated receptor-gamma coactivator 1 alpha (PGC-1 alpha): transcriptional coactivator and metabolic regulator. Endocr Rev 24:78-90 
25. Hammarstedt A, Jansson PA, Wesslau C, Yang X, Smith U (2003) Reduced expression of PGC-1 and insulin-signaling molecules in adipose tissue is associated with insulin resistance. Biochem Biophys Res Commun 301:578-582

26. Speakman JR (2004) Obesity: the integrated roles of environment and genetics. J Nutr 134:2090S-2105S

27. Ktorza A, Bernard C, Parent V et al (1997) Are animal models of diabetes relevant to the study of the genetics of non-insulindependent diabetes in humans? Diabetes Metab 23(Suppl 2): $38-46$

28. Yoon JC, Xu G, Deeney JT et al (2003) Suppression of beta cell energy metabolism and insulin release by PGC-1alpha. Dev Cell 5:73-83

29. Tiraby C, Tavernier G, Lefort C et al (2003) Acquirement of brown fat cell features by human white adipocytes. J Biol Chem 278:33370-33376

30. Yang X, Enerback S, Smith U (2003) Reduced expression of FOXC2 and brown adipogenic genes in human subjects with insulin resistance. Obes Res 11:1182-1191

31. Coulter AA, Bearden CM, Liu X, Koza RA, Kozak LP (2003) Dietary fat interacts with QTLs controlling induction of Pgc-1 alpha and Ucp1 during conversion of white to brown fat. Physiol Genomics 14:139-147
32. Rhee J, Inoue Y, Yoon JC et al (2003) Regulation of hepatic fasting response by PPARgamma coactivator-1alpha (PGC-1): requirement for hepatocyte nuclear factor 4alpha in gluconeogenesis. Proc Natl Acad Sci U S A 100:4012-4017

33. Herzig S, Hedrick S, Morantte I, Koo SH, Galimi F, Montminy M (2003) CREB controls hepatic lipid metabolism through nuclear hormone receptor PPAR-gamma. Nature 426:190-193

34. Oberkofler H, Schraml E, Krempler F, Patsch W (2004) Restoration of sterol-regulatory-element-binding protein-1c gene expression in HepG2 cells by peroxisome-proliferatoractivated receptor-gamma co-activator-1alpha. Biochem J 381: $357-363$

35. Gupta G, Cases JA, She L et al (2000) Ability of insulin to modulate hepatic glucose production in aging rats is impaired by fat accumulation. Am J Physiol Endocrinol Metabol 278: E985-E991

36. Browning JD, Horton JD (2004) Molecular mediators of hepatic steatosis and liver injury. J Clin Invest 114:147-152

37. Gavrilova O, Haluzik M, Matsusue K et al (2003) Liver peroxisome proliferator-activated receptor gamma contributes to hepatic steatosis, triglyceride clearance, and regulation of body fat mass. J Biol Chem 278:34268-34276 